Reprod. Nutr. Dévelop. 1980, 20 (4 A), 1025-1039.

\title{
Protéolyse in vitro de caséine et de gluten par les enzymes pancréatiques
}

\author{
par Marie-Claire CAMUS, J. C. LAPORTE, \\ avec la collaboration technique de P. POCHOLLE. \\ Unité de Recherches sur lo Nufrition ef l'Alimentation, \\ U. 1. de I'INSERM, Hôpital Bichat, \\ 170 Bd. Ney, F-75877 Paris Cédex 18.
}

Summary. In vitro proteolysis of casein and gluten by pancreatic enzymes.

The time-course of proteolysis of casein and gluten by pancreatic enzymes (trypsin, chymotrypsin, pancreatic juice) was studied in vitro with various concentrations of enzyme or substrate. The effect of a previous peptic proteolysis, with or without sodium phytate, on proteolysis by pancreatic juice was also studied. Proteolysis was evaluated by measuring the nitrogen in products solubilized in trichloroacetic acid (peptides + amino acids) and in phosphotungstic acid (amino acids).

Without a previous peptic proteolysis, at a low enzyme/substrate ratio, the release of peptides and amino acids was greater for casein than for gluten. At a high enzyme/substrate ratio, peptide release by pancreatic juice and chymotrypsin was quite similar for casein and gluten but amino acid release was a little less for gluten.

After a previous high peptic proteolysis without sodium phytate, pancreatic juice proteolysis, at a low enzyme/substrate ratio, was increased. Peptide release was similar for casein and gluten but amino acid release was a little less for the gluten. With sodium phytate, the release of peptides was quite similar for casein but was less for gluten. The release of amino acids was diminished in both cases.

Thus, gluten was more resistant than casein to the action of pancreatic enzymes. Nevertheless, this was not necessarily observed when those enzymes were used for proteolysis at a high enzyme/substrate ratio or following a high peptic proteolysis.

The differences between casein and gluten proteolyses have been discussed according to the specific action of the pancreatic enzymes.

In conclusion, in comparing the proteolyses of various foods, it is important to use various enzyme/substrate ratios.

\section{Introduction.}

La protéolyse de la caséine et du gluten par les enzymes pancréatiques donne lieu à des résultats souvent opposés lorsque leur action est précédée de celle de la pepsine.

Dans une étude antérieure in vitro (Camus et al., 1973), nous observions pour le gluten, comme Zimmermann-Nielsen et Schonheider (1962) pour l'une de ses fractions protéiques, la gliadine, une dégradation par la trypsine moindre que celle de la 
caséine, et de plus, une atténuation très nette des différences entre ces deux substrats soumis préalablement à l'action de la pepsine. De même, après une protéolyse pepsique, les valeurs obtenues pour le gluten par Blanc (1977), avec un mélange trypsine + chymotrypsine, ou par Akeson et Stahman (1964), avec de la pancréatine, sont inférieures à celles de la caséine. Par contre, celles obtenues par Moutonnet (1967) ou par Suschetet (1969), avec un mélange trypsine + peptidases, sont soit égales dans les deux cas soit le plus souvent supérieures pour le gluten.

In vivo, les expériences réalisées par Rogers et al., (1960) chez le rat, montrent que la teneur en azote total des contenus intestinaux, dans les heures suivant l'ingestion de caséine ou de gliadine, est faible et du même ordre sauf au temps 2 heures où elle est un peu plus forte pour la gliadine. Des résultats analogues sont observés, chez le rat, par Rolls ef al. (1972) et, chez le porc, par Zebrowska (1973) pour les teneurs en azotes insolubles et soluble des contenus intestinaux.

Dans un premier essai d'explication de ces résultats pouvant être liés à des conditions différentes de protéolyse par la pepsine et/ou par les enzymes pancréatiques, nous avons montré qu'en augmentant le rapport enzyme/substrat et la durée de la réaction, les différences de protéolyse entre la caséine et le gluten disparaissaient avec la pepsine (Camus et Sautier, 1972) et diminuaient avec la trypsine (Camus et al., 1973). Par ailleurs, nous avons mis en évidence l'importance pour la caséine et surtout pour le gluten, d'une action de la pepsine préalable à celle de la trypsine (Camus et al., 1973) et une inhibition de leur protéolyse pepsique par le phytate de sodium (Camus et Laporte, 1976).

Notre objectif a donc été de rechercher d'abord les effets du rapport enzyme/ substrat et de la durée de la réaction sur la protéolyse de ces deux substrats par les enzymes pancréatiques seules ou associées (trypsine, chymotrypsine, suc pancréatique) puis ceux d'une protéolyse préalable par la pepsine, avec ou sans phytate, sur celle par du suc pancréatique.

La quantité et la nature des produits de la réaction peuvent différer pour un même substrat selon les enzymes et pour une même enzyme selon les substrats. Aussi, pour évaluer la protéolyse, nous avons dosé l'azote des produits solubles dans les acides trichloracétique (peptides + acides aminés) et phosphotungstique (acides aminés).

Cette éfude analytique devrait donc permettre de déterminer si le gluten soumis à la seule action des enzymes pancréatiques peut subir une proféolyse équivalente ou supérieure à celle de la caséine ou si ce résultat ne peut être obtenu que si l'action de ces enzymes est précédée de celle de la pepsine.

\section{Matériel et méthodes.}

a) Matériel.

1) Substrats.

Teneur en azole

en p. $100 \mathrm{du}$ poids frais

(Méthode de Kjeldahl)

Caséine Hammarsten (Merck) ......

13,8

Gluten de blé (Prolabo) ..........

12,8 
2) Enzymes.

- Pepsine de porc cristallisée Worthington (2 600 unités $/ \mathrm{mg}$ ) ;

- Trypsine de bœuf cristallisée Armour (3 500 unités $/ \mathrm{mg}$ ) ;

- Chymotrypsine de bœuf lyophilisée Armour (1500 unités/mg) ;

- Suc pancréatique de rat obtenu par fistules (Laporte et Trémolières, 1973), activé spontanément à $-20^{\circ} \mathrm{C}$, de concentrations en trypsine $(3,5 \mathrm{mg} / \mathrm{ml})$ et en chymotrypsine $(4,0 \mathrm{mg} / \mathrm{ml})$, déterminées respectivement sur benzoylarginine-p-nitroanilide ou BAPNA (Bieth et al., 1966) et sur succinyl-phénylalanine-p-nitroanilide ou SUPHEPA (Bieth et al., 1968), par référence à des enzymes pures Armour.

3) Effecteur: Phytate de sodium anhydre I.C.N.

b) Méthodes.

1) Conditions expérimentales. Les expériences avec les enzymes pancréatiques, sans protéolyse pepsique préalable, sont faites à $37^{\circ} \mathrm{C}$, dans une solution de Krebs Ringer bicarbonatée (*) (Umbreit et al., 1957), de pH 7,3, saturée en carbogène, sous agitation magnétique.

Le volume du milieu réactionnel est de $25 \mathrm{ml}$. Les concentrations finales du substrat et de l'enzyme pure ou incluse dans le suc pancréatique ainsi que la durée de la réaction sont indiquées, pour chaque expérience, dans les figures correspondantes.

Aux divers temps, on prélève 100 à $500 \mu l$ du milieu réactionnel que l'on ajoufe, sous agitation, à un volume égal d'acide trichloracétique 1,2 $\mathrm{M}$ ou d'acide phosphotungstique $0,02 \mathrm{M}$, contenu dans un microtube plastique Eppendorf de 1,5 $\mathrm{ml}$. Après un temps de contact de $10 \mathrm{~min}$ environ, entre le réactif de précipitation et le milieu réactionnel, on centrifuge à $980 \mathrm{~g}$, puis on dose l'azote du surnageant selon la méthode de Berthelot (Sautier, 1973), après minéralisation en milieu sulfurique concentré, avec $\mathrm{SO}_{4} \mathrm{CU}$ et $\mathrm{SO}_{4} \mathrm{~K}_{2}$, comme catalyseurs.

Une éventuelle protéolyse pepsique préalable a lieu à $37^{\circ} \mathrm{C}$, à $\mathrm{pH} 2,0$, en milieu chlorhydrique, sous agitation magnétique.

Le volume du milieu réactionnel est de $12,5 \mathrm{ml}$ avec des concentrations finales du substrat, de l'enzyme et de l'effecteur éventuel, respectivement de $4 \mathrm{mg} / \mathrm{ml}$ en azote, $1 \mathrm{mg} / \mathrm{ml}$ en pepsine, $25 \mathrm{mg} / \mathrm{ml}$ en phytate de sodium. Après $1 \mathrm{~h}$ de protéolyse pepsique, le milieu réactionnel est ajusté à $\mathrm{pH} 7,3$ par $\mathrm{NaOH}$ environ $0,02 \mathrm{~N}$ en concentration finale et complété à $25 \mathrm{ml}$ par une solution de Krebs bicarbonate de concentration double.

2) Statistiques. Les moyennes $(\mathrm{m})$ suivies de l'écart-type de la moyenne $\left(\mathrm{s}_{\mathrm{m}}\right)$ et du nombre d'expériences $(n)$ sont comparées en déterminant par le test $F$ la significativité de leurs différences. Ces différences sont dites très significatives pour un seuil de probabilité $P \leqslant 0,01$, significatives pour $0,01<P \leqslant 0,05$, non significatives pour $P>0,05$.

$\left(^{*}\right)$ Cette solution a été choisie en raison d'une étude ultérieure d'absorption intestinale in vitro par incubation de segments de jéjunum retourné de rat dans divers protéolysats ici obtenus. En conséquence, ces protéolysats devaient avoir une composition en électrolytes aussi physiologique que possible et être suffisamment oxygénés. 


\section{Résultats.}

1) Protéolyse par du suc pancréatique.

a) A concentration variable de l'enzyme ef constante du substrat (fig. 1).

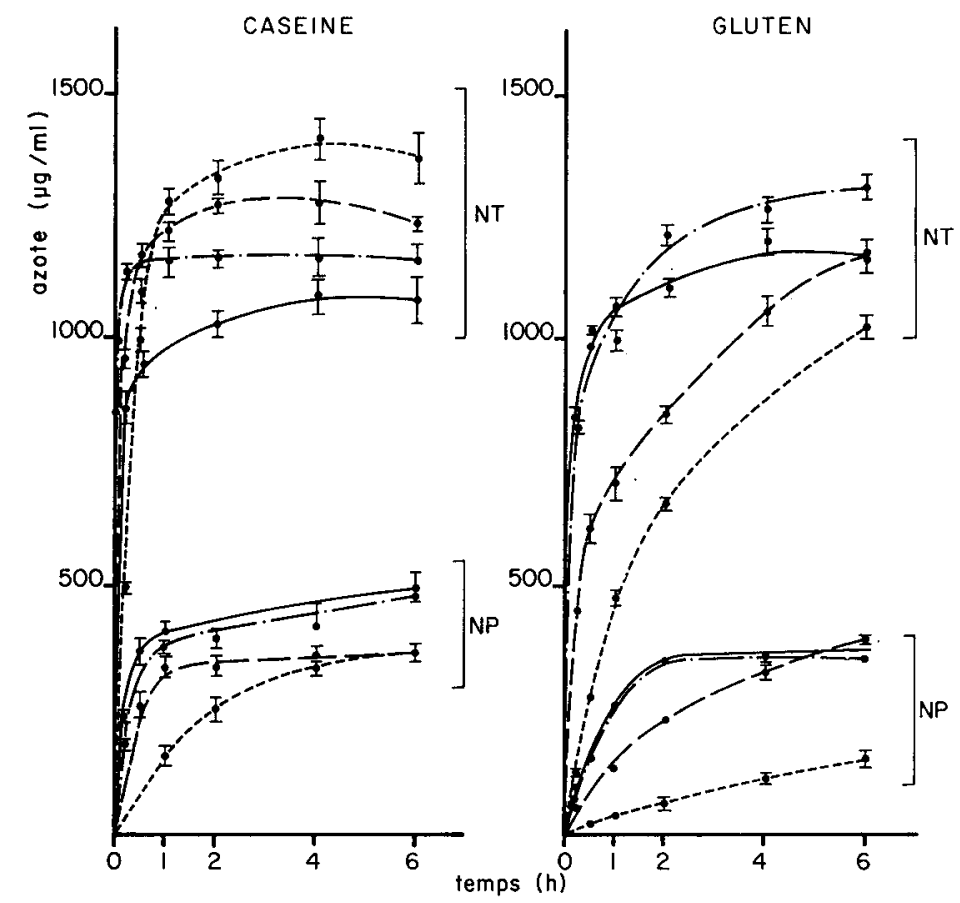

FIG. 1. - Protéolyse par du suc pancréatique, à concentrations variable de l'enzyme ef constante du substrat. Azotes solubles dans les acides trichloracétique 0,6 M(NT) et phosphotungstique 0,01 $\mathrm{M}(\mathrm{NP})$; $m \pm s_{m}(n=6)$.

Milieu Krebs bicarbonate, température $37^{\circ} \mathrm{C}$, azote $2,0 \mathrm{mg} / \mathrm{ml}$, suc pancréatique en $\mathrm{mg} / \mathrm{ml}$ de trypsine incluse : - $-0,01 ;---0,04 ;-\cdots-0,16 ;-0,64$.

Azote soluble dans l'acide trichloracétique. - Aux faibles concentrations de l'enzyme $(0,01-0,04 \mathrm{mg} / \mathrm{ml})$, la libération de l'azote soluble dans l'acide trichloracétique est plus grande pour la caséine que pour le gluten $(P \leqslant 0,01)$, de l'ordre de 2 à 4 fois en début de réaction (15-30 min). Ces différences diminuent quand la concentration de l'enzyme augmente et même disparaissent $(P>0,05)$ pour la plus forte d'entre elles $(0,64 \mathrm{mg} / \mathrm{ml})$.

Pour le gluten, la libération de cet azote augmente $(P \leqslant 0,01)$ en fonction de la concentration de l'enzyme, de 0,01 à $0,16 \mathrm{mg} / \mathrm{ml}$. Pour la caséine, ce résultat obtenu en début de réaction, s'inverse aux temps les plus longs : d'une manière inattendue, c'est avec les concentrations les plus faibles de l'enzyme que l'on observe en fin de réaction les valeurs les plus élevées. 
Azote soluble dans l'acide phosphotungstique. - La libération de l'azote soluble dans l'acide phosphotungstique est très inférieure à la précédente, de l'ordre de 100 fois en début de réaction ( $15 \mathrm{~min}$ ), pour la plus faible concentration de l'enzyme. Elle est plus grande aussi pour la caséine que pour le gluten $(P \leqslant 0,01)$ et les différences sont d'autant plus importantes que la concentration de l'enzyme est faible. Pour ces deux substrats, elle augmente proportionnellement à la concentration de l'enzyme lorsque celle-ci ne dépasse pas $0,04 \mathrm{mg} / \mathrm{ml}$ ).

b) A concentrations constante de l'enzyme et variable du substrat (fig. 2).

Azote soluble dans l'acide trichloracétique. - Pour la caséine, quand la concentration du substrat augmente, la libération de l'azote soluble dans l'acide trichloracétique augmente aux temps 15 et $30 \mathrm{~min}(P \leqslant 0,01)$, et les courbes de protéolyse deviennent sigmoïdales.

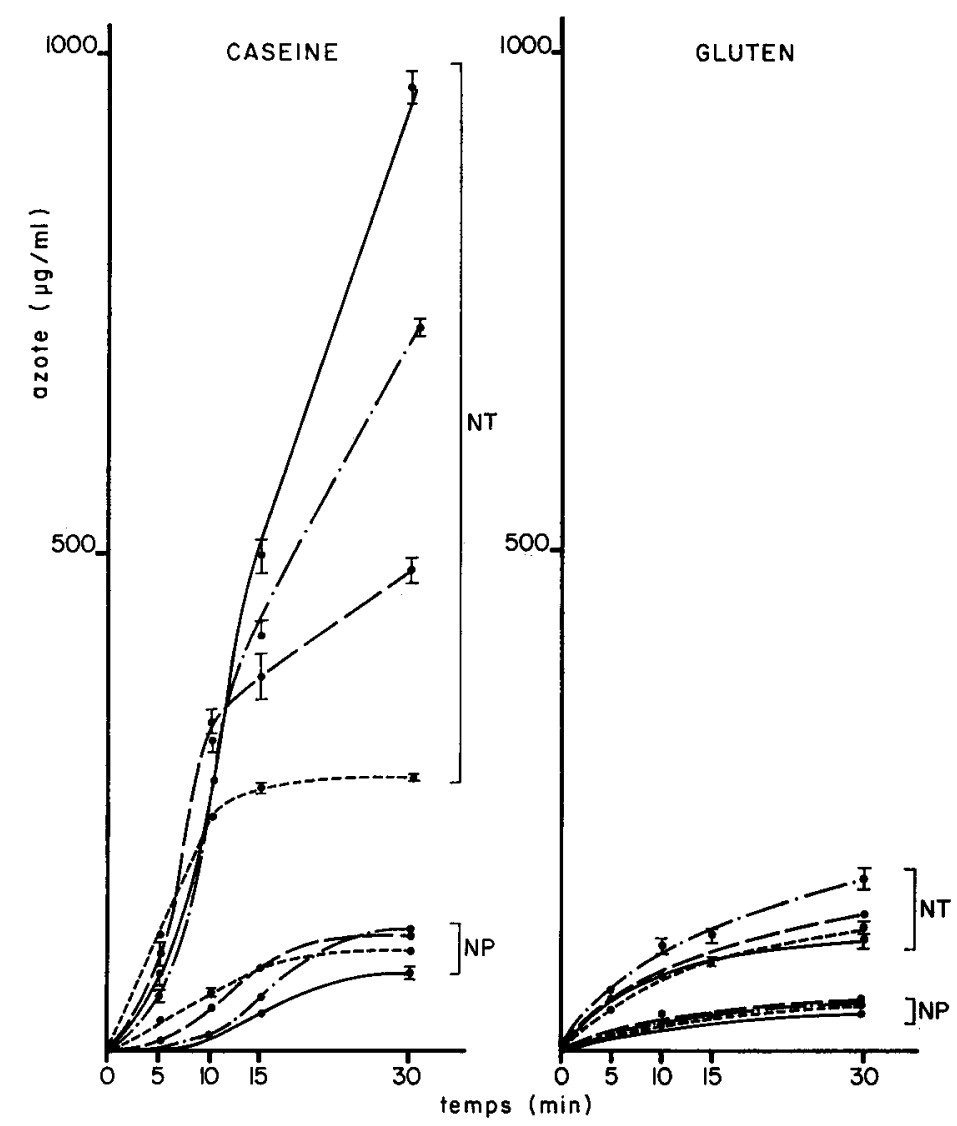

FIG. 2. - Protéolyse par du suc pancréatique, à concentrations constante de l'enzyme ef variable du substrat. Azotes solubles dans les acides trichloracétique $0,6 \mathrm{M}(\mathrm{NT})$ et phosphotungstique $0,01 \mathrm{M}(\mathrm{NP})$; $m \pm s_{m}(n=6)$.

Milieu Krebs bicarbonate, température 37 o $\mathrm{C}$, azote en $\mathrm{mg} / \mathrm{ml}:--0,5 ;-\infty-1,0 ;-\cdot-$ 2,$0 ;-4$; suc pancréatique $0,01 \mathrm{mg} / \mathrm{ml}$ de trypsine incluse. 
Pour le gluten, elle ne dépend pas de la concentration du substrat $(P>0,05)$ et demeure inférieure à celle observée pour la caséine $(P \leqslant 0,01)$.

Azote soluble dans l'acide phosphotungstique. - La libération de l'azote soluble dans l'acide phosphotungstique est inférieure à la précédente, de l'ordre de 2 à 10 fois selon les cas. Elle est presque toujours moindre pour le gluten que pour la caséine, sauf aux temps 5 et $10 \mathrm{~min}$, pour lesquels, aux fortes concentrations du substrat, un résultat inverse est observé.

Pour la caséine, la libération de cet azote est moindre aux fortes qu'aux faibles concentrations du substrat, surtout en début de réaction $(P \leqslant 0,01)$ et l'on observe là encore une sigmoïdicité des courbes de protéolyse.

Pour le gluten, les résultats sont analogues à ceux obtenus pour l'azote soluble dans l'acide trichloracétique.

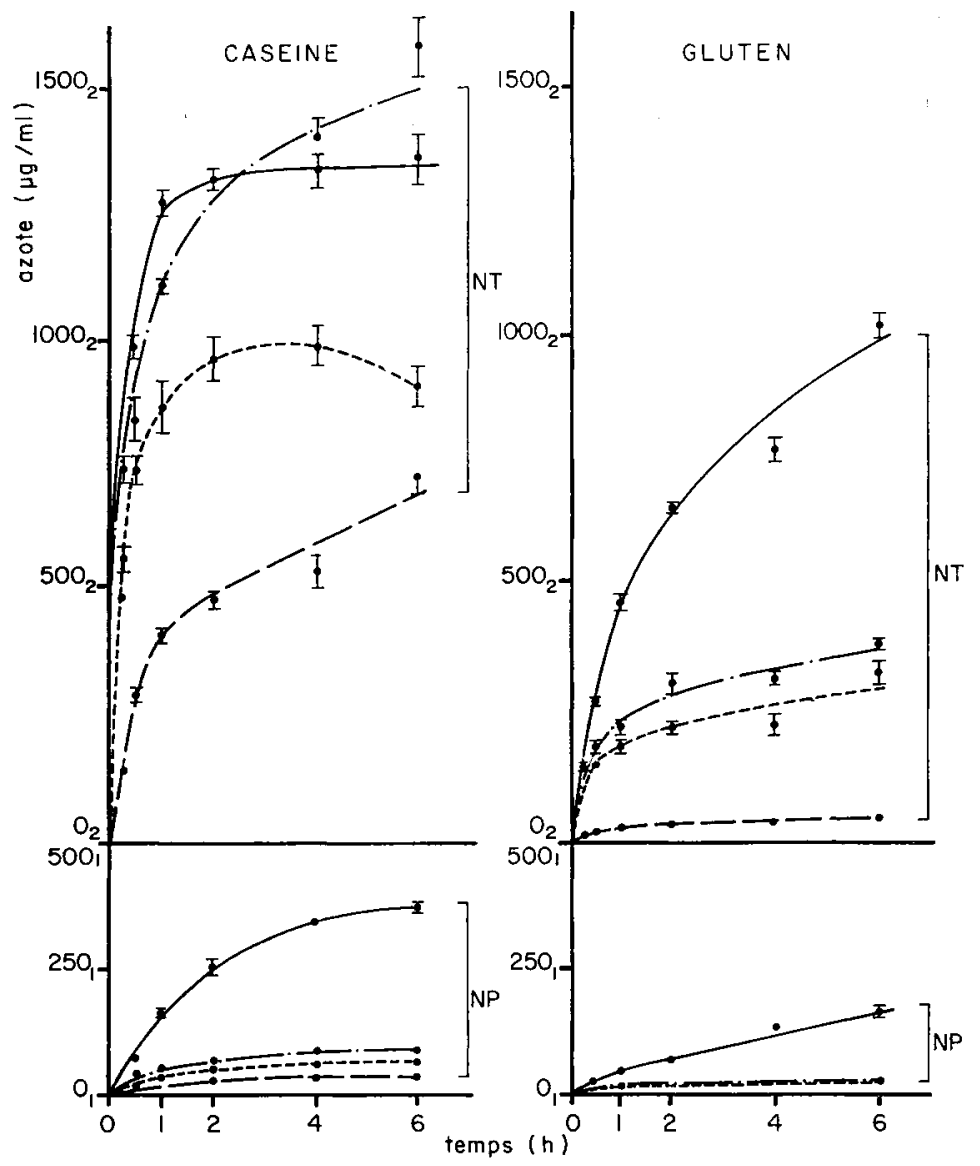

FIG. 3. - Protéolyse por du suc pancréatique, de la trypsine ou de la chymotrypsine de même concentration que dans le suc, à concentrations constantes de l'enzyme et du substrat. Azotes solubles dans les acides trichloracétique $0,6 \mathrm{M}(\mathrm{NT})$ et phosphotungstique $0,01 \mathrm{M}(\mathrm{NP}) ; \mathrm{m} \pm \mathrm{s}_{\mathrm{m}}(\mathrm{n}=6)$.

Milieu Krebs bicarbonate, température $37^{\circ} \mathrm{C}$, azote $2,0 \mathrm{mg} / \mathrm{ml}$, trypsine en $\mathrm{mg} / \mathrm{ml}:---0,01$; chymotrypsine en $\mathrm{mg} / \mathrm{ml}:-\ldots-0,005 ;$ trypsine + chymotrypsine en $\mathrm{mg} / \mathrm{ml}:-\bullet-0,01+0,005$; suc pancréatique en $\mathrm{mg} / \mathrm{ml}$ de trypsine ef de chymotrypsine incluses : $-0,01+0,005$. 
2) Protéolyse par du suc pancréatique, de la trypsine ou de la chymotrypsine de même concentration que dans le suc, à concentrations constantes de l'enzyme et du isubstrat (fig. 3).

Azote soluble dans l'acide trichloracétique. - La libération de l'azote soluble dans l'acide trichloracétique est plus grande pour la caséine que pour le gluten $(\mathrm{P}: \leqslant 0,01)$, de l'ordre de 15 fois ou plus avec la chymotrypsine et de 5 fois ou plus avec les autres enzymes. Pour le suc pancréatique, les différences entre les deux substrats diminuent quand la durée de la réaction augmente.

Les résultats obtenus avec le suc pancréatique ou le mélange trypsine + chymotrypsine sont analogues pour la caséine $(P>0,05)$ mais non pour le gluten dont la protéolyse est nettement plus importante dans le premier cas $(P \leqslant 0,01)$.

Azote soluble dans l'acide phosphotungstique. - La libération de l'azote soluble dans l'acide phosphotungstique est faible : environ 20 p. 100 de l'azote total sont solubilisés dans cet acide par le suc pancréatique après $6 \mathrm{~h}$ de réaction et seulement $1 \mathrm{p} .100 \mathrm{par}$ la trypsine, la chymotrypsine ou leur mélange. Là encore, comme précédemment, elle est plus grande pour la caséine que pour le gluten $(P \leqslant 0,01)$. Pour ces deux substrats, elle esł plus importante avec le suc pancréatique qu'avec le mélange trypsine + chymotrypsine $(P \leqslant 0,01)$.

3) Protéolyse par de la trypsine, à concentrations variable de l'enzyme ef constante du substrat (fig. 4).

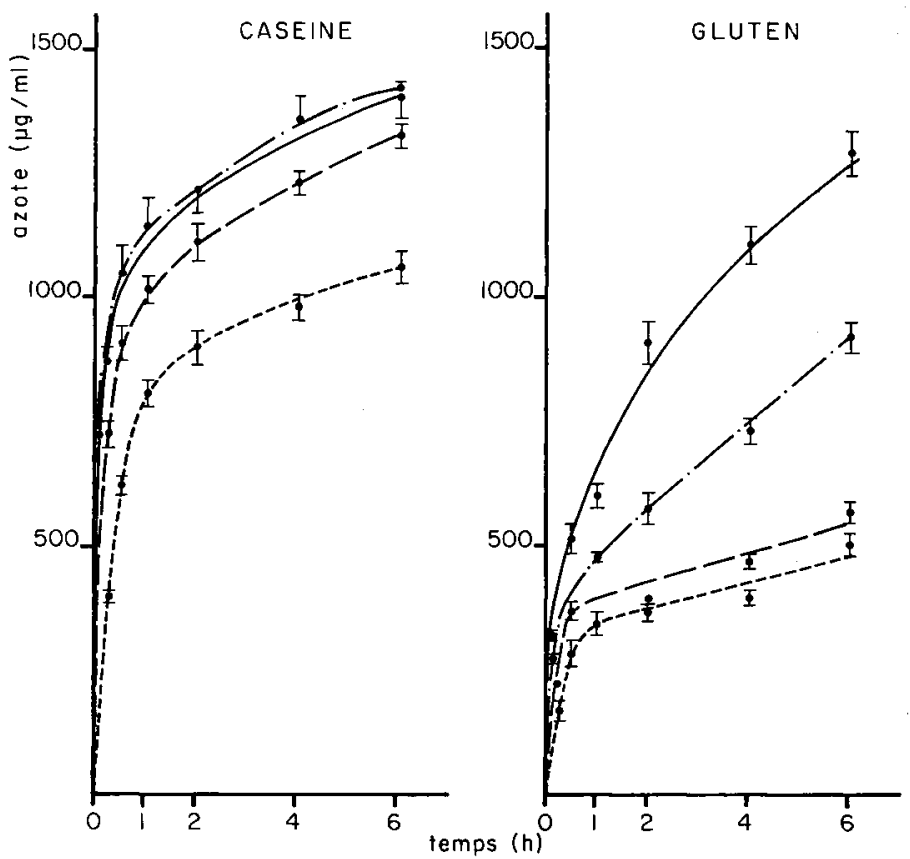

FIG. 4. - Protéolyse par de la trypsine, à concentrations variable de l'enzyme et constante du substrat. Azote soluble dans l'acide trichloracétique $0,6 \mathrm{M} ; \mathrm{m} \pm s_{\mathrm{m}}(\mathrm{n}=6)$.

Milieu Krebs bicarbonate, température $37^{\circ} \mathrm{C}$, azote $2,0 \mathrm{mg} / \mathrm{ml}$, trypsine en $\mathrm{mg} / \mathrm{ml}:---0,01$; $--0,04 ;-\cdot-0,16 ;-0,64$. 
Azote soluble dans l'acide trichloracéfique. - La libération de l'azote soluble dans l'acide frichloracétique est environ 2 à 3 fois plus grande pour la caséine que pour le gluten $(P \leqslant 0,01)$ sauf aux fortes concentrations de l'enzyme $(0,16,0,64 \mathrm{mg} / \mathrm{ml})$ où en fin de réaction les différences sont moindres et tendent à disparaître.

Pour le gluten, elle augmente en fonction de la concentration de l'enzyme $(P \leqslant 0,01)$ et, pour la caséine, seulement aux faibles concentrations $(0,01,0,04 \mathrm{mg} / \mathrm{ml})$.

4) Protéolyse par de la chymotrypsine, à concentrations variable de l'enzyme ef constante du substrat (fig. 5).

Azote soluble dans l'acide trichloracétique. — Aux faibles concentrations de l'enzyme $(0,005,0,02 \mathrm{mg} / \mathrm{ml})$ la libération de l'azote soluble dans l'acide trichloracétique est environ 15 à 20 fois plus grande pour la caséine que pour le gluten $(P \leqslant 0,01)$.

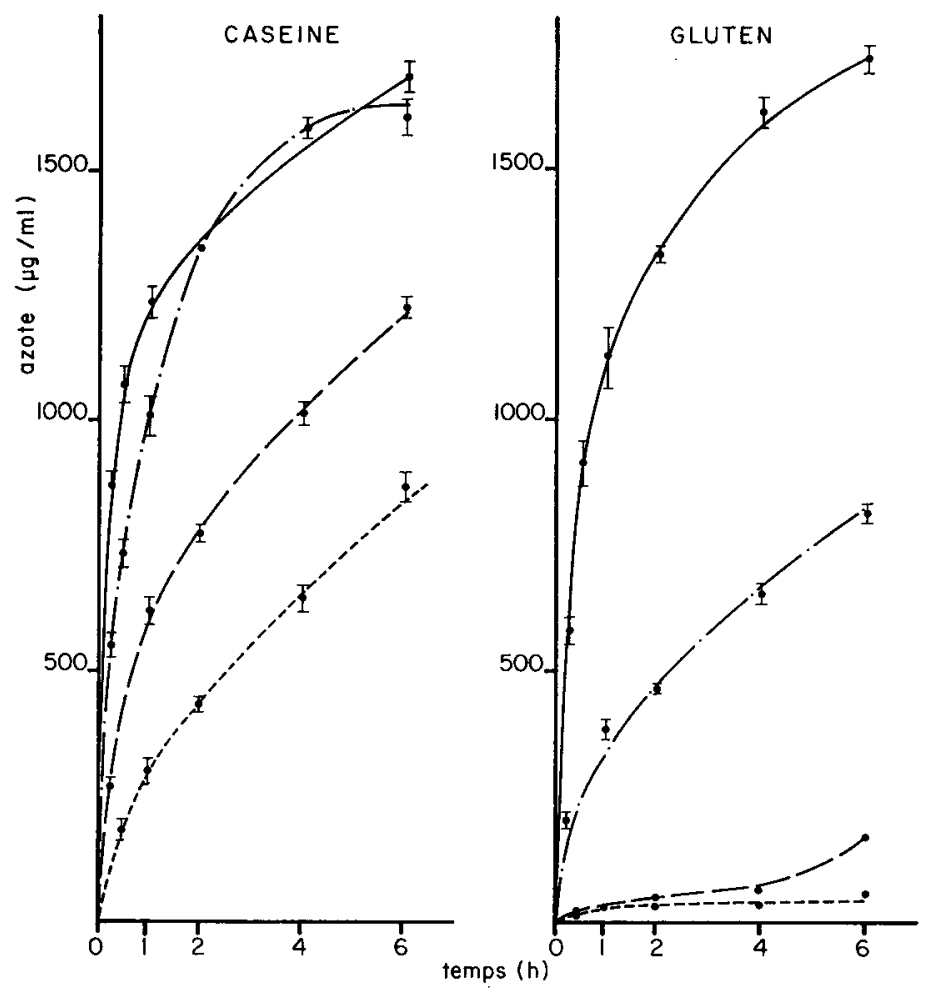

FIG. 5. - Protéolyse par de la chymotrypsine, à concentrations variable de l'enzyme et constante du substrat. Azote soluble dans l'acide trichloracétique $0,6 \mathrm{M} ; \mathrm{m} \pm \mathrm{s}_{\mathrm{m}}(\mathrm{n}=6)$.

Milieu Krebs bicarbonate, température $37^{\circ} \mathrm{C}$, azote $2,0 \mathrm{mg} / \mathrm{ml}$, chymotrypsine en $\mathrm{mg} / \mathrm{ml}:--0,005$; $--0,02 ;-\cdot-0,08 ;-0,32$.

Aux fortes concentrations de l'enzyme $(0,08,0,32 \mathrm{mg} / \mathrm{ml})$, les différences entre ces deux substrats diminuent, voire même disparaissent.

La libération de cet azote augmente en fonction de la concentration de l'enzyme $(P \leqslant 0,01)$, surtout pour le gluten. 
5) Protéolyse par de la trypsine à concentrations constante de l'enzyme ef voriable du substrat (fig. 6).

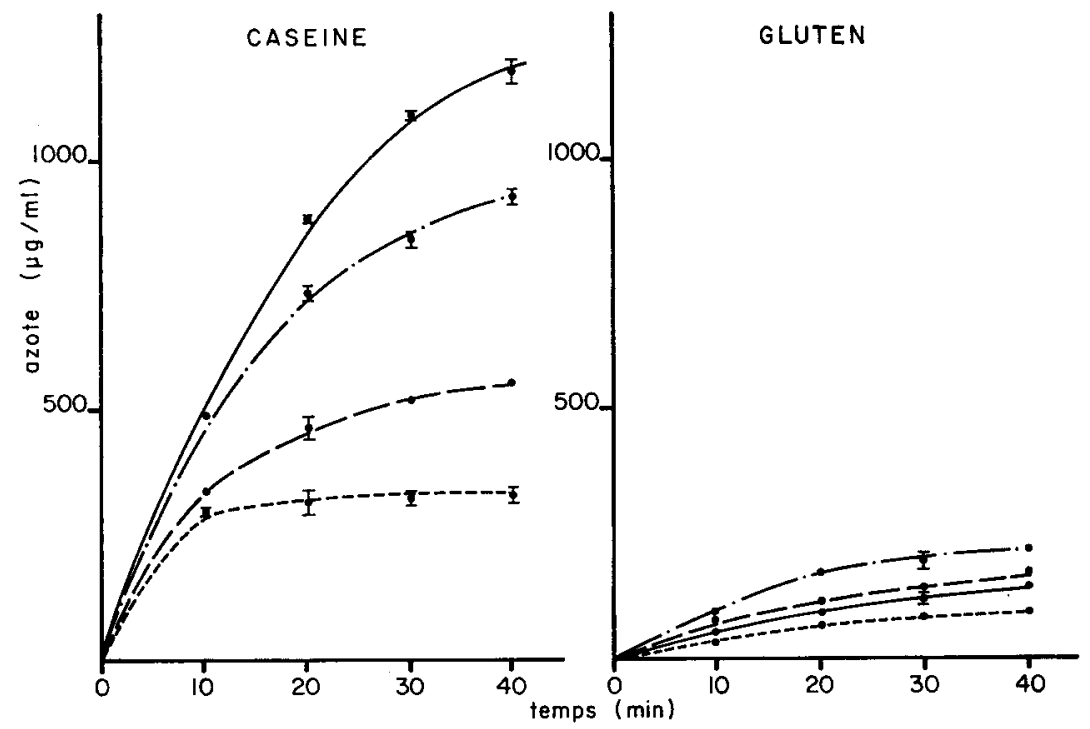

FIG. 6. - Protéolyse par de la trypsine, à concentrations constante de l'enzyme et variable du substrat. Azote soluble dans l'acide trichloracétique $0,6 \mathrm{M} ; \mathrm{m} \pm \mathrm{s}_{\mathrm{m}}(\mathrm{n}=6)$.

Milieu Krebs bicarbonate, température $37{ }^{\circ} \mathrm{C}$, azote en $\mathrm{mg} / \mathrm{ml}:--0,5 ;---1,0 ;-\cdots-2,0$; 4,$0 ;$ trypsine : $0,01 \mathrm{mg} / \mathrm{ml}$.

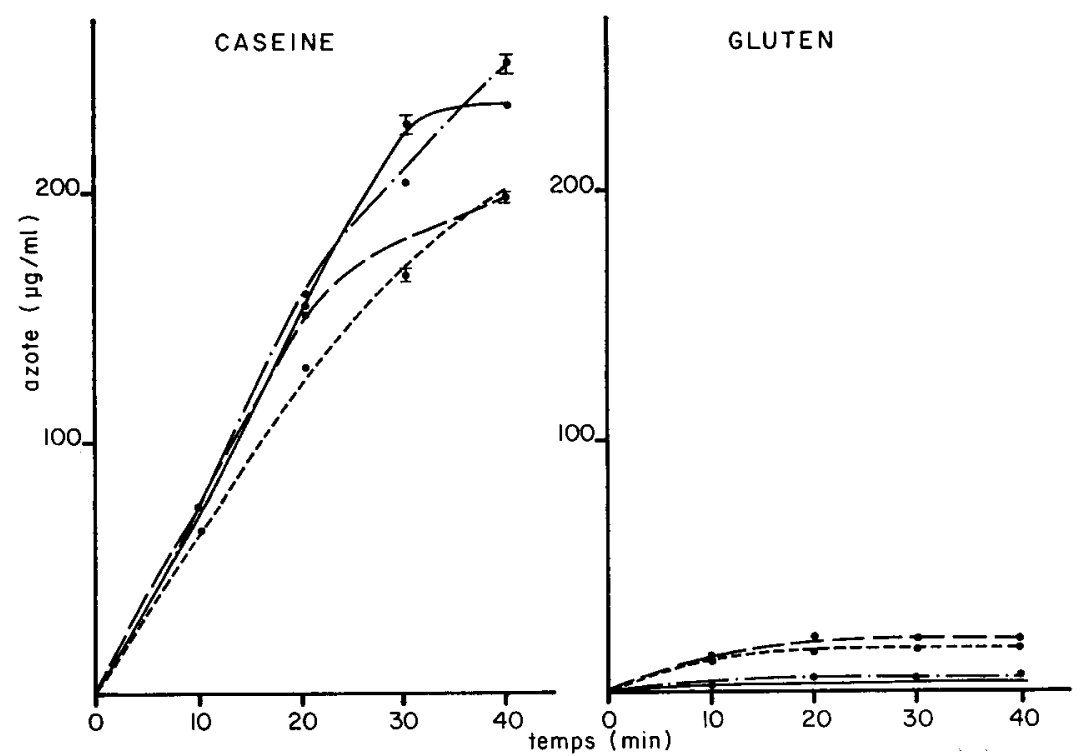

FIG. 7. - Protéolyse par de la chymotrypsine, à concentrations constante de l'enzyme et variable du substrat. Azote soluble dans l'acide trichloracétique $0,6 \mathrm{M} ; \mathrm{m} \pm \mathrm{s}_{\mathrm{m}}(\mathrm{n}=6)$.

Milieu Krebs bicarbonate, température $37{ }^{\circ} \mathrm{C}$, azote en $\mathrm{mg} / \mathrm{ml}:--0,5 ;--1,0 ;-\cdots-2,0$; - 4,0; chymotrypsine : $0,005 \mathrm{mg} / \mathrm{ml}$. 
Azote soluble dans l'acide trichloracétique. - La libération de l'azote soluble dans l'acide trichloracétique augmente en fonction de la concentration du substrat $(P \leqslant 0,01)$. Cependant pour le gluten, à une concentration de $4 \mathrm{mg} / \mathrm{ml}$ en azote, elle est environ 1,5 fois plus faible qu'à une concentration 2 fois moindre $(P \leqslant 0,01)$. Elle est plus grande aussi pour la caséine que pour le gluten $(P \leqslant 0,01)$ de l'ordre de 3 à 4 fois et même davantage lorsque la concentration du substrat est de $4 \mathrm{mg} / \mathrm{ml}$ en azote.

6) Protéolyse par de la chymotrypsine, à concentrations constante de l'enzyme et variable du substrat (fig. 7).

Azote soluble dans l'acide trichloracétique. - Pour la caséine, la libération de l'azote soluble dans l'acide trichloracétique augmente en fonction de la concentration du substrat mais moins nettement qu'avec la trypsine. Par contre, pour le gluten, elle est plus grande aux faibles qu'aux fortes concentrations.

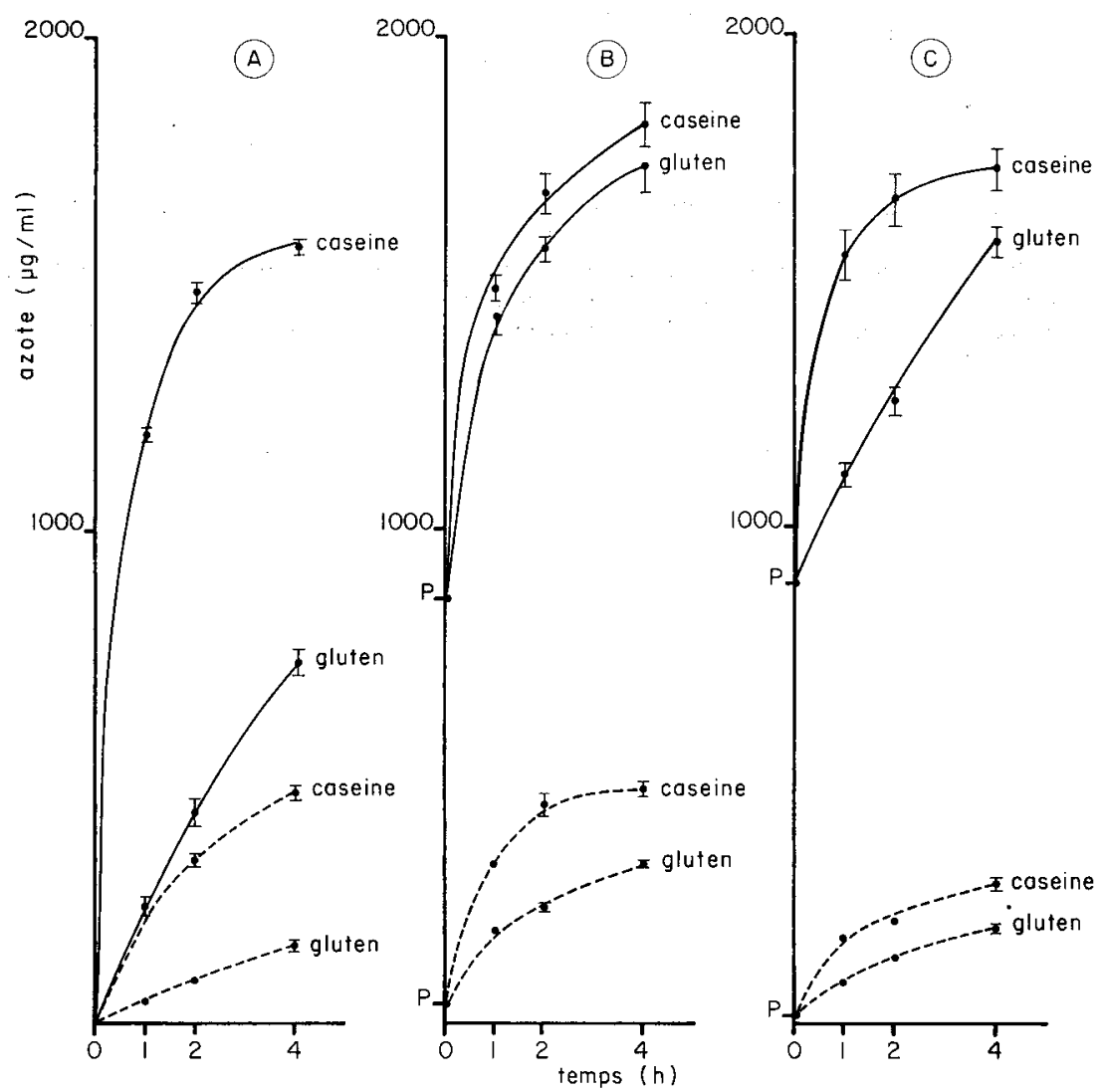

FIG. 8. - Protéolyse par du suc pancréatique, seule (A) ou après une protéolyse pepsique en absence (B) ou en présence de phyfate de sodium (C), à concentrations constantes de l'enzyme et du substrat. Azotes solubles dans les acides trichloracétique $0,6 \mathrm{M}$ et phosphotungstique $0,01 \mathrm{M} ; \mathrm{m} \pm \mathrm{s}_{\mathrm{m}}(\mathrm{n}=6)$.

Protéolyse pepsique (P) ; Protéolyse par du suc pancréatique : Milieu Krebs bicarbonate, température $37{ }^{\circ} \mathrm{C}$, azote $2,0 \mathrm{mg} / \mathrm{ml}$; suc pancréatique : $0,01 \mathrm{mg} / \mathrm{ml}$ de trypsine incluse, —— azote soluble dans l'acide trichloracétique ; - - azote soluble dans l'acide phosphotungstique. 
7) Protéolyse par du suc pancréatique, seule ou après une protéolyse pepsique en absence ou en présence de phytate de sodium, à concentrations constantes de l'enzyme et du substrat (fig. 8).

Azote soluble dans l'acide trichloracétique. - Avec ou sans phytate de sodium, le pourcentage de l'azote solubilisé dans l'acide trichloracétique par la pepsine est le même pour la caséine et le gluten $(P>0,05)$, de l'ordre de $45 \mathrm{P}$. 100. Sans protéolyse pepsique préalable, la libération de cet azote par le suc pancréatique est de 2 à 5 fois plus grande pour la caséine que pour le gluten $(P \leqslant 0,01)$, les différences entre ces deux substrats diminuant avec la durée de la réaction.

Avec protéolyse pepsique préalable et sans phytate, cette libération est augmentée, surtout pour le gluten $(P \leqslant 0,01)$ et les différences entre ces deux substrats disparaissent $(P>0,05)$. Avec phytate, elle est du même ordre pour la caséine mais non pour le gluten pour lequel elle devient plus faible que sans phytate $(P \leqslant 0,01)$ et comparable à celle observée sans protéolyse pepsique préalable $(P>0,05)$.

Azote soluble dans l'acide phosphotungstique. Pour la caséine et le gluten, les pourcentages de l'azote solubilisé dans l'acide phosphotungstique par la pepsine sont respectivement de 2 ef 1 p. 100 en absence ef en présence de phytate de sodium.

Sans protéolyse pepsique préalable, la libération de cet azote par le suc pancréatique est environ 3 à 5 fois plus grande pour la caséine que pour le gluten $(P \leqslant 0,01)$, les différences diminuent là encore avec la durée de la réaction.

Avec protéolyse pepsique préalable et sans phytate, cette libération est augmentée, surtout pour le gluten $(P \leqslant 0,01)$. Si elle demeure plus grande pour la caséine que pour le gluten, les différences sont cependant moindres que sans protéolyse pepsique. Avec phytate, elle est plus faible pour les deux substrats $(P \leqslant 0,01)$ surtout pour la caséine pour laquelle elle devient inférieure $(P \leqslant 0,01)$ à celle observée sans protéolyse pepsique préalable.

\section{Discussion.}

Pour évaluer la protéolyse, nous avons dosé l'azote des produits de la réaction solubles dans les acides trichloracétique et phosphotungstique.

D'après Cristol et Puech (1926). Puech et Cristol (1926), l'acide trichloracétique ne précipite que les protéines et l'acide phosphotungstique, les protéines ef les polypeptides. Cependant, l'action de ces acides peut ne pas être aussi sélective. Si l'acide trichloracétique, à une concentration de 10 p. 100, équivalente à celle utilisée dans nos expériences, ne précipite presque exclusivement que les protéines et des polypeptides de haut poids moléculaire (Yon, 1963), l'acide phospholungstique peut avoir une action beaucoup plus forte que celle lui étant attribuée par Cristol et Puech. En effet, Van Slyke et al. (1942) montrent que, dans certaines conditions, cet acide précipite les acides diaminés (lysine, arginine, histidine) basiques, les acides monoaminés étant plus solubles. Néanmoins, cefte précipitation d'acides diaminés, même avec un rapport optimum acide aminé/acide phosphotungstique, requiert plusieurs heures pour être complète. Or, dans nos expériences, le femps de contacr entre l'acide phosphotungstique et le protéolysat est seulement de l'ordre de $10 \mathrm{~min}$. II est donc probable qu'une part importante des acides diaminés basiques et, a fortiori, des autres acides 
aminés, reste alors en solution. Ces réserves faites, nous assimilerons l'azote soluble dans l'acide trichloracétique à celui des peptides et des acides aminés, ef l'azote soluble dans l'acide phosphotungstique, à celui des acides aminés.

Nos résultats montrent que si les concentrations de trypsine et de chymotrypsine, pures ou incluses dans le suc pancréatique ou plus précisément, si les rapports enzyme/ substrat sont faibles $(\leqslant 1 / 100)$, la libération de peptides par ces enzymes est moindre pour le gluten que pour la caséine.

De plus, avec la trypsine et la chymotrypsine pures, utilisées à de très faibles concentrations, les valeurs obtenues pour le gluten diminuent quand sa concentration augmente, ce qui pourrait être dû à une inhibition par excès de substrat.

Avec un rapport enzyme/substrat plus fort $(\geqslant 1 / 40)$ et une durée de réaction suffisamment longue (60 min), la libération des peptides peut être du même ordre pour la caséine et le gluten, avec le suc pancréatique et la chymotrypsine, mais non avec la trypsine avec laquelle les différences subsistent. De même, ZimmermannNielsen et Schonheider (1962) utilisant, pour la trypsine, un rapport enzyme/substrat élevé $(1 / 20)$ observent une protéolyse moindre pour le gluten que pour la caséine.

Pour le suc pancréatique, avec un faible rapport enzyme-substrał $(1 / 1000)$, nous obtenons un résultat analogue au précédent, si son action est précédée d'une protéolyse pepsique relativement importante (45 p. 100 de l'azote total solubilisé dans l'acide trichloracétique). Par contre, la libération d'acides aminés par le suc pancréatique utilisé soit avec un fort rapport enzyme/substrat, soit après la protéolyse pepsique précédente, et quelle que soit la durée de la réaction, reste inférieure pour le gluten.

In vitro, Moutonnet (1967) et Suschetet (1969), utilisant un rapport enzyme/ substrat de $1 / 20$, constatent que les quantités d'azote $\alpha$-aminé libéré lors de la protéolyse pepsique puis lors de celle par un mélange trypsine + peptidases, sont, soit égales pour la caséine ef le gluten, soit supérieures pour ce dernier. Or, dans nos expériences, si nous adoptons, pour la pepsine, un rapport enzyme/substrat très voisin $(1 / 25)$, les différences de protéolyse entre les deux substrats précédents disparaissent aussi bien pour cette enzyme que pour le suc pancréatique lui succédant.

La libération d'azote $\alpha$-aminé plus importante pour le gluten, obtenue par Moutonnet ef Suschetet avec un mélange trypsine +- peptidases, peut être en rapport avec la protéolyse pepsique préalable, aussi plus importante dans ce cas. En effet, on remarque qu'après soustraction des valeurs de protéolyse pepsique, celles dues au mélange trypsine + peptidases sont voisines pour les deux substrats.

Des résultats analogues in vivo sont observés par Rolls ef al. (1972) chez le rat, puisque la teneur en azote soluble des contenus intestinaux est un peu plus faible pour la caséine que pour le gluten, alors que celle des contenus stomacaux est très nettement supérieure pour ce dernier. En outre, les quantités d'acides aminés, mesurées dans le sang de la veine porte par ces auteurs sont environ 2 fois moindres pour le gluten que pour la caséine, ce qui indique probablement pour cette dernière une dégradation plus complète par les enzymes pancréatiques. Or, c'est effectivement ce que montrent nos expériences in vitro où l'action des peptidases n'intervient pas. Ces résultats mettent en évidence, notamment pour le gluten, l'importance du niveau de protéolyse pepsique préalable, lors de son attaque par les enzymes pancréatiques. L'utilisation d'un faible rapport enzyme/substrat de l'ordre de 1/100 avec la pepsine puis avec un mélange 
trypsine + chymotrypsine par Blanc (1977) pourrait expliquer les valeurs de protéolyse moindres pour le gluten que pour la caséine.

II apparaît donc que le gluten est intrinsèquement moins facilement attaquable que la caséine par les enzymes pancréatiques, ceci pouvant être masqué par un excès d'enzyme ou une action préalable importante de la pepsine conduisant à une même libération de peptides.

Cette différence entre la caséine et le gluten peut provenir de leurs différences de teneur en acides aminés spécifiquement impliqués dans les liaisons sécables par les enzymes pancréatiques. Ainsi, la teneur du gluten en lysine, 5 fois moindre que celle de la caséine, et en arginine, un peu inférieure (Altman et Dittmer, 1968), peut rendre compte des valeurs de protéolyse pour la trypsine et la carboxypeptidase B dont les spécificités d'action sont très étroites. Peuvent aussi intervenir certains acides aminés adjacents à ceux impliqués dans les liaisons sécables par la trypsine (proline, acide glutamique, cystéine), la chymotrypsine (acide glutamique, cystéine), la carboxypeptidase A (proline, acide glutamique), la carboxypeptidase B (proline, alanine) en réduisant ou en bloquant l'action de ces enzymes.

Ainsi, les protéolysats de gliadine, obtenus par actions successives de pepsine, d'enzymes pancréatiques (trypsine + chymotrypsine + carboxypeptidases) et de peptidases intestinales, comportent des peptides de type pyroglutamyl- $x-x_{n}$ où $x$ est de la proline ou de l'acide glutamique (Biserte et Han, 1965). De même, des protéolysats de gliadine ou de gluténine, obtenus par action de la pepsine, de la pronase ou par actions successives de la pepsine et de la pronase, comportent des peptides pyroglutamiques constitués surtout de proline pour la gliadine et de glycine pour la gluténine (Bietz et Rothfus, 1971).

Dans ce travail, la protéolyse préalable par la pepsine a été faite avec un rapport enzyme/substrat de 1/25 identique à celui utilisé dans un travail antérieur (Camus et al., 1973), mettant en évidence une diminution des différences entre la caséine et le gluten lors d'une protéolyse trypsique ultérieure. Ce rapport est supérieur à ceux utilisés dans un autre travail (Camus et Laporte, 1976) mettant en évidence une inhibition de la protéolyse pepsique de la caséine et du gluten par l'acide phytique. Ceci explique, sans doute, qu'ici, l'inhibition de la protéolyse pepsique de la caséine et du gluten n'apparaît que pour la libération d'acides aminés et non de peptides. De même, l'action du suc pancréatique sur la caséine ef le gluten, venant après celle de la pepsine est moindre en présence de phytate, surtout pour la libération des acides aminés. Ceci peuł provenir d'une action moindre des carboxy- et amino-peptidases, liée à une action préalable de la pepsine et à une fixation par le phytate d'ions bivalents $\left(\mathrm{Mg}^{++}\right.$, $\mathrm{Mn}^{++}, \mathrm{Zn}^{++}$) nécessaires à leur activité.

\section{Conclusion.}

La protéolyse de la caséine et du gluten par des enzymes pancréatiques isolées (trypsine, chymotrypsine) ou en mélange (suc pancréatique) dépend d'une éventuelle action préalable de la pepsine ef du rapport enzyme/substrat.

Sans action préalable de la pepsine, pour de faibles valeurs de ce rapport $(\leqslant 1 /$ $100)$, la libération de peptides et d'acides aminés est plus petite pour le gluten que pour 
la caséine. Pour de fortes valeurs de ce rapport $(\geqslant 1 / 40)$, la libération de peptides par du suc pancréatique ou de la chymotrypsine devient la même dans les deux cas mais non celle par la trypsine qui reste plus petite pour le gluten, avec toutefois des différences moindres. Toujours pour de fortes valeurs de ce rapport, la libération d'acides aminés, due essentiellement à l'action du suc pancréatique, est inférieure pour le gluten mais là aussi avec des différences moindres.

Après une protéolyse pepsique importante et identique pour les deux substrats, les résultats relatifs au suc pancréatique, pour de faibles valeurs du rapport enzyme/ substrat, deviennent analogues à ceux obtenus sans action préalable de la pepsine, pour de fortes valeurs de ce rapport. L'adjonction de phytate de sodium lors de la protéolyse pepsique est sans effet sur la libération de peptides alors qu'elle diminue celle des acides aminés. Lors de l'action ultérieure du suc pancréatique, c'est surtout la libération des acides aminés qui se trouve diminuée.

II ressort que le gluten est donc moins facilement attaquable que la caséine par les enzymes pancréatiques. Ceci peut être masqué par un excès d'enzyme ou une action préalable importante de la pepsine, du moins si l'on ne considère que la libération des peptides.

Pour comparer la protéolyse de divers aliments, il apparaît donc important de faire varier les conditions expérimentales. Ainsi, en déterminant la nature des produits de la réaction libérés à divers temps par les enzymes pancréatiques, pour diverses valeurs du rapport enzyme/substrat, il est possible d'expliquer les résultats parfois divergents obtenus in vitro et in vivo lors de la protéolyse de la caséine et du gluten par ces enzymes.

Reçu en juin 1979

Acceplé en février 1980.

\section{Références}

ALTMAN P. L., DITTMER D. S., 1968. Metabolism, 53-59. Fed. Amer. Soc. exp. Biol., Bethesda.

AKESON W. R., STAHMAN M. A., 1964. A pepsine pancreatine digest index of protein quality evaluation. J. Nutr., 83, 257-261.

BIETH J., METAIS P., WARTER J., 1966. Ełude des protéases pancréatiques. I. Dosage de la trypsine par la benzoyl-arginine p-nitroanilide et ses applications. Ann, Biol. clin., 24, 787-803.

BIETH J., METAIS P., WARTER J., 1968. Etude des protéases pancréatiques. II. Dosage de la chymotrypsine par la succinyl-phenylalanine et ses applications. Ann. Biol. clin., 26, 143-158.

BIETZ J. A., ROTHFUS J. A., 1971. Difference in amino acid sequences of gliadin and glutenin. Cereal Chem., 48, 677-690.

BISERTE G., HAN K., 1965. Peptides résiduels de l'hydrolyse enzymatique de la gliadine du blé. Bull. Soc. Chim. biol., 47, 597-609.

BLANC B., 1977. Digestibility of proteins. Ann. Bull. int. Dairy Fed., 94, 28-31.

CAMUS M. C., LAPORTE J. C., 1976. Inhibition de la protéolyse pepsique in vitro par le blé. Rôle de l'acide phytique des issues. Ann. Biol. anim. Bioch. Biophys., 16, 714-729.

CAMUS M. C., LAPORTE J. C., SAUTIER C., 1973. Protéolyse trypsique in vitro de divers aliments. Ann. Biol. anim. Bioch. Biophys., 13, 193-202.

CAMUS M. C., SAUTIER C., 1972. Protéolyse pepsique d'aliments d'origine animale et végétale. Ann. Biol. anim. Bioch. Biophys., 12, 281-288.

CRISTOL P., PUECH A., 1926. Indice de polypeptidémie et indice de désamination. C. R. Soc. Biol., 95, 1401-1402.

LAPORTE J. C., TREMOLIÈRES J., 1973. Action de la trypsine ef des inhibiteurs trypsiques sur la sécrétion pancréatique. Nutr. Métabol., 15, 192-206. 
MOUTONNET P., 1967. Influence des sulfites sur la protéolyse : étude in vitro. Ann. Biol. anim. Bioch. Biophys., 7, 63-71.

PUECH A., CRISTOL P., 1926. A propos de l'indice de désamination. Signification de l'indice de polypeptidémie et de l'indice de désamination. Soc. Méd. Hôp. Paris, L (3e série), 1928-1934.

ROGERS Q. R., CHEN M. L., PERAINO C., HARPER A. E., 1960. Observations on protein digestion in vivo. III. Recovery of nitrogen after feeding diets containing different proteins. J. Nutr., $\mathbf{7 2}$, 331-339.

ROLLS B. A., PORTER J. W. G., WESTGARTH D. R., 1972. The course of digestion of different food proteins in the rat. 3. The absorption of proteins given alone and with supplements of their limiting amino acids. Brit. J. Nutr., 28, 283-293.

SAUTIER C., 1973. Ełude quantitative des fèces. In OLIVIER, H. R., Traité de Biologie appliquée, V, 128-129, Maloine, Paris.

SUSCHETET M., 1969. Influence des produits solubles formés par chauffage du glucose et du glycocolle sur l'hydrolyse enzymatique de différentes protéines. Ann, Biol. anim. Bioch. Biophys., 9 , 405-412.

UMBREIT W. W., BURRIS R. H., STAUFFER J. F., 1957. Manometric techniques, 149, Burgess Publ.

VAN SLYKE D. D., HILLER A., DILLON R. T., 1942. Solubilities and compositions of the phospho-12tungstates of the diamino acids and of proline, glycine, and tryptophane. J. biol. Chem., 146, 137-157.

YON J., 1963. Etude des réactions enzymatiques. In LOISELEUR J., Techniques de laborafoire, I (2), 955 , Masson Paris.

ZEBROWSKA T., 1973. Influence of dietary protein source on the rate of digestion in the small intestine of pigs. Part. I. Amount and composition of digesta. Rocz. Nauk Pol., B-95-1, 115-133.

ZIMMERMANN-NIELSEN C., SCHONHEIDER F., 1962. On the rate of disappearance of protein from the small intestine in vivo. Biochim. biophys. Acta, 63, 201-203. 